Adrienne Simpson was a Stout Resident in 1989 and 1990, and is working on topics relating to operatic and theatrical history. Major articles of hers have recently been published in $N Z$ Women's Studies Journal, Music in New Zealand and The Turnbull Record. She is the editor of Opera in New Zealand: Aspects of History and Performance which is forthcoming, and has made contributions to The New Grove Dictionary of Opera and The International Dictionary of Opera, which are also forthcoming.

Jane Tolerton, a freelance writer, came to the Stout Centre in 1987 to write a biography of Ettie Rout, the New Zealander best known for her 'safe sex' campaign among the ANZAC troops during World War One. In 1988-89 she and Nicholas Boyack, formed the WWI Oral History Archive and interviewed about 90 veterans. The tapes are now in the Alexander Turnbull Library and the resulting book, In The Shadow of War, was published by Penguin Books in April 1990. Jane is now working again on the biography which she expects to finish by the end of the year.

Dorothea Turner (b. Christchurch 1910) has written a biography, Jane Mander (Twayne, 1972), a practical monograph for New Zealand hand-spinners and weavers, Ways into Woolcraft (1978), a dissertation on Herodotus' syntax for her $\mathrm{PhD}$ (VUW, 1989), and is now working on a discontinuous memoir, Embargoed Till Midnight.

Brenda Watson became associated with Stout researchers in 1988. She is one of Wellington's most accomplished transcribers and word-processers. Her work appears in records of the Oral History Archive and in publications by Stout fellows: In the Shadow of War by Nicholas Boyack and Jane Tolerton; The Treaty Now by Bill Renwick; The Book of New Zealand Women eds Charlotte Macdonald, Merimeri Penfold \& Bridget Williams; The Matriarchs by Judith Fyfe.

\title{
'Tacking Through the Gusts' : Methodology in multi-cultural and multi-disciplinary research
}

WENDY POND

Resident Research Scholar at School of Biological Sciences

In this paper I chronicled my progress towards bicultural scholarship. First, I created models for fieldwork out of my own experience of growing up in this country. I allowed my research to be directed by the priorities of the society I worked in. Then I saw the harm being done by my own society and acted to counter it, establishing systematic principles of classification in Austronesian languages and giving scientific definition to Māori names of insects, to ensure their continuing use.

Then I approached Mäori knowledge from the perspective of a compatible culture: a culture with an intellectually contenious tradition, a strong poetic - metaphorical tradition, and a coherent tradition of ancient wisdom teachings.

In field work, I collaborated with New Zealand entomologists and ecologists who already have a strong sense of New Zealand scholarship, reflecting the uniqueness of the New Zealand environment.

Many scientists continue to assert the superiority of western explanations of reality, and continue to believe that their perceptions are unbiased by cultural priorities. They cannot countenance the transmission of forces between the natural and social realms, nor the transmission of knowledge through metaphore, and cannot see that dismissing Māori knowledge without investigating it, is unscientific. I noted that anthropologists and historians 
knowledge without investigating it, is unscientific. I noted that anthropologists and historians make analyses of shifts of power in Pacific societies while ignoring the astute and sardonic running commentary on political affairs made by Māori and Polynesian composers in their dance-songs. The analysis of social polity in Polynesian song-texts challenges anthropological explanation, but the challenge goes unanswered.

I gave an example of a way in which bicultural science can immediately be got underway. A shift towards bicultural research will come when priorities set by Mãori capture scientific effort.

During fieldwork in Northland, I concluded that Māori are hindered by lack of confidence in themselves and in their culture. Establishing confidence in Māori knowledge is a priority in bicultural science.

Sailing gave me skills of fieldwork appropriate amongst descendants of the Austronesian seafarers : to think on my feet, to meet challenges to the work; sailing gave me knowledge of one set of metaphors through which Austronesian people structure human relationships and communicate scientific ideas.

From a Stout Centre seminar on 30 May 1990

\section{Trying to teach dynamics in a reasonable way: a suggested method for schools and universitties}

\section{NORMAN BARBER \\ Professor Emeritus of Physics, Victoria University of Wellington}

Isaac Newton understood why planets circled around the sun instead of travelling away in straight lines. They were all falling towards the sun just as smaller objects near earth fall towards the earth. Newton could not explain how the sun could exert, an influence across great lengths of empty space, but he claimed that the strength and direction of the unknown influence (which he called a 'force') should be judged by the 'amount of motion' that it created. Unfortunately he never explained his reasons for this opinion. We are left to guess.

I urge that 'amount of motion' should be an early study of dynamics. It can be taught by using a collection of trolleys running on almost frictionless wheels. The amount of substance in each should be adjusted till any two trolleys starting at rest recoil at equal speeds when a spring is released between them. Then we know that they have equal inertia (equal mass). Perhaps each one might amount to one kilogram. The trolleys need not be alike in design or materials, but just in mass.

When the spring is released between stationary trolleys, a single one and a 'double' one (two tied together), the double one recoils less quickly. Its speed proves to be just half the speed of the single one. Yet one may claim that the 'amount of motion' is the same on both sides of the spring, arguing that two kilograms recoiling at half speed possess as much motion as one kilogram recoiling at full speed. One can try other combinations of trolleys and find that the spring always generates equal (and opposite) amounts of motion on its two sides.

The short English name for 'amount of motion' is 'momentum'. The momentum of a moving object is its velocity multiplied by the number of kilograms moving at that velocity. When objects collide and recoil it is as if some spring had briefly been trapped between the two. So momentum is gained by one object and the other gains an equal but opposite amount. The result is that the total amount of momentum has not changed. This rule is called the 'conservation of momentum'. Momentum like velocity is a vector quantity, and the rule holds no matter in what directions the different objects are moving. Many situations in dynamics can be discussed through this rule. It might be called the first rule of dynamics. Newton was 